\title{
A NOÇÃO DE PROBLEMA EM FILOSOFIA'
}

\author{
ÉMILE BRÉHIER
}

Tradutor: Pedro Jonas de Almeida²

A palavra problema é, em nossos dias, empregada com uma singular frequência. Uma vez que apareça a menor dificuldade, se fabrica com ela um problema: problema colonial, problema fiscal, problema do abastecimento e assim por diante. Somos cotidianamente assediados por essas expressões. Acreditar-seia que, ao tomar a palavra de empréstimo das ciências exatas, pudéssemos introduzir mais rigor na formulação das dificuldades e estivéssemos, assim, um pouco mais próximos de resolvê-las. Os filósofos não são os últimos a utilizá-la. Em todos os casos onde, outrora, se utilizava as palavras teoria ou doutrina, hoje encontramos a palavra mais modesta problema: problema do ser, problema do conhecimento, da ciência, problema moral, problema religioso. Os filósofos alemães empregam com frequência a palavra Problematik para designar uma disciplina que diz respeito à maneira de formular os problemas. É perfeitamente natural que o sucesso dessa expressão tenha provocado a reunião do Instituto internacional de filosofia em 1947, em Lund, para abordar o tema: $O$ problema do problema. Com efeito, é possível que esse êxito inclusive denote uma característica bem importante da orientação filosófica atual.

$\mathrm{Na}$ Antiguidade, a palavra só era empregada quase que exclusivamente pelos matemáticos no sentido técnico que ela conservou. Se examinarmos o Comentário sobre Euclides 
de Proclus ${ }^{3}$, que é muito bem informado acerca da história das matemáticas, encontraremos nele que, por oposição ao teorema que pretende deduzir uma propriedade de um ser matemático a partir de sua essência, dada na definição, o problema busca construir uma grandeza em sua relação com outras (por exemplo, dividir um segmento de reta em média e extrema razão) e a solução nos faz presenciar a gênese dessa grandeza. A expressão se estende até a astronomia matemática e o próprio Platão a emprega na República ${ }^{4}$ para designar a investigação da combinação de círculos em movimento uniforme que devem explicar a aparência do movimento variado dos planetas. Mas um platônico como Espeusipo se recusa a empregá-la e deseja que, em Geometria, tudo seja teorema, pois o problema nos anuncia a geração de uma grandeza e "não há geração nas coisas eternas" . Há, na coleção das obras de Aristóteles, uma compilação intitulada Problemas, da qual a data é tardia (V ou VI século, estima Léon Robin) e cujo título, por conseguinte, não é de Aristóteles. Ela inclui, além de problemas matemáticos, questões relativas à biologia e à moral. Mas, como ocorre nas matemáticas, o problema sempre se refere a uma questão concreta, limitada, definida, cuja formulação inclusive supõe a pré-existência da ciência no interior da qual ele é formulado, ciência que irá fornecer os meios de resolvê-lo. Desse modo, o problema possui apenas um lugar restrito.

Há, entretanto, uma exceção que é de extrema importância: nos Tópicos, essa obra consagrada à arte da discussão, Aristóteles define assim o problema ${ }^{6}$ : "a diferença entre o problema e a proposição está na maneira de formular a questão. Se dissermos, por exemplo, 'animal pedestre e bípede 
é a definição de homem, não é?', obteremos uma proposição. Se, ao contrário, dissermos: 'animal pedestre e bípede é, ou não, a definição de homem?', teremos aí um problema”. Dito de outro modo, enquanto a definição contempla apenas uma tese que pedimos que seja admitida, o problema considera como possível o contrário da tese proposta e reivindica ao mesmo tempo que se faça o exame dos argumentos favoráveis e contrários a essa tese. O problema é essencialmente dialético e, por essa razão, bastante útil para a filosofia, porque "a possibilidade de acrescentar aos problemas argumentos nos dois sentidos, dar-nos-á a possibilidade de descobrir, de modo mais fácil, a verdade e o erro em cada caso". Portanto, o problema é, antes de mais nada, consciência de uma alternativa $^{7}$. Ele põe o espírito contra si mesmo. Além disso, estamos aqui, sem dúvida, diante de um dos pontos de partida da filosofia. A filosofia começou quando as afirmações da consciência espontânea sobre o homem e sobre o universo se tornaram problemáticas ${ }^{8}$.

O carpinteiro, o arquiteto e o escultor sabem o que é a matéria sobre a qual trabalham. O camponês e o marinheiro sabem o que são os elementos, a terra, o mar, a atmosfera, que lhes resistem ou lhes são favoráveis. O homem religioso que, por intermédio dos ritos, está em relação com o seu deus, fica assegurado de sua existência, e todas essas relações vitais (no sentido pleno da palavra) engendram nesses tipos uma variedade imensa de problemas práticos que só a experiência pode resolver. Mas nenhum deles sonha em formular, em relação a esses objetos que lhes ocupam a vida inteira, os problemas filosóficos que formularam os Jônios ou seus sucessores para si mesmos: o que é a matéria? Qual é a origem 
dos elementos? Os deuses existem e qual é a natureza deles? É que não há, da perspectiva de todos os acima indicados, alternativa: a matéria, os elementos e o deus se impõem como realidades indiscutíveis. Para que haja problema, é preciso começar duvidando que essas realidades sejam no fundo o que parecem ser, que tenham sempre a forma que agora possuem, é preciso, em suma, que haja uma alternativa: a matéria é isto ou não é isto? Deus existe ou não?

Nota-se que, como o problema matemático supõe uma ciência que lhe seja anterior, também o problema dialético supõe um conjunto de afirmações no interior das quais ele emerge. Dito de outro modo, a problemática sempre supõe o "meta-problemático". Porém, o meta-problemático não é o mesmo nos dois casos: na dialética ele não é constituído por afirmações científicas certas, mas de opiniões mais ou menos prováveis conforme sejam tradicionais ou não, de todos ou de alguns, de sábios ou de ignorantes. Se, para resolver o problema dialético, não temos senão (isto é, para escolher um dos lados da alternativa) materiais desse gênero, ele nunca será resolvido de modo rigoroso e a incerteza das premissas reaparecerá na conclusão. A filosofia assumirá, então, o risco de permanecer no plano da exposição antitética das razões pro e contra, sem nada concluir. É exatamente isso o que se deu com os sofistas dos séculos V e IV a.c. O ceticismo posterior, que se renovou várias vezes até nossos dias, também se mostra complacente com essa situação. Mesmo fora do ceticismo, a exposição dialética do pró e do contra é ao menos considerada como um exercício preliminar indispensável à filosofia, como se verifica nos artigos sucessivos da Suma Teológica de São Tomás, para não mencionar a aposta de Pascal, a antitética da 
razão pura de Kant, os dilemas metafísicos de Renouvier. O famoso exercício da segunda parte do Parmênides [de Platão] é, segundo uma interpretação a que plenamente me associo, uma estilização desse procedimento dialético, mostrando que podemos afirmar ou negar tudo da tese de Parmênides sobre a unidade do ser e [afirmar ou negar tudo] do contrário dessa tese.

Talvez a filosofia não tivesse saído dessa situação sem Sócrates. Os diálogos socráticos de Platão nos mostram um Sócrates dialético, está certo, mas que de algum modo interioriza o debate dialético através do exame que faz de seu interlocutor. Ele cria nesse último a consciência penosa de uma contradição íntima. O pró e o contra, ao invés de ser cada um sustentado por um adversário distinto, se revela à consciência como sendo interior a ela mesma, como uma dissociação que ela não pode suportar. O problema está, desse modo, em escapar da opinião instável, de revisar essa metaproblemática, que é responsável por essa incerteza. A função de Sócrates foi a de fazer experimentar a contradição íntima como uma dor e quase como um remorso. O problema da meta-problemática, ou, para ser mais claro, a descoberta das afirmações filosóficas certas, removidas, por sua natureza, do exame dialético... - esse foi e continua sem dúvida sendo o problema filosófico essencial. Fazer sua história seria fazer a história de toda nossa filosofia: a visão platônica do Bem, as ideias claras em Descartes, o fato primitivo em Maine de Biran, a estrutura dialética do espírito em Hegel, o valor da ciência no positivismo, a intuição bergsoniana, todos esses fatores originais do pensamento filosófico pertencem à metaproblemática. As filosofias às quais nos referimos são filosofias 
que não admitem a alternativa e cujo desenvolvimento se faz, poderíamos dizer, antes por teoremas do que por problemas? Diante de um tema tão amplo, ficarei satisfeito com as observações sucintas a seguir, com o fim de esclarecer as teses que precedem:

1. Sabe-se quais precauções são necessárias, em filosofia, para formular um problema e o quanto é mais fácil do que em outros domínios deslizar nos pseudoproblemas ou nos problemas insolúveis. A atividade dos pensadores de maior envergadura, a de Kant, por exemplo, consistiu sobretudo em se dedicar a modificar a formulação dos problemas e ele a fez quando se deu conta que a meta-problemática, em que se alcançava sua solução, os fazia desaparecer em vez de resolvê-los. Por exemplo, subordinar a solução do problema moral a perspectivas teóricas sobre a natureza ou sobre Deus, significa fazêlo desaparecer, ao negligenciar o caráter essencial da vontade moral, a saber, a autonomia ${ }^{10}$. Aqui o problema desaparece por uma espécie de $\mu \varepsilon \tau \dot{\alpha} \beta \alpha \sigma \iota \varsigma$

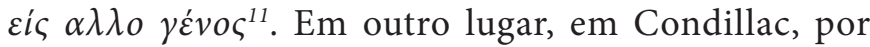
exemplo, o problema desaparece por uma redução abusiva, quando os fenômenos mais complexos da consciência são considerados como se fossem uma sensação transformada. Como podemos verificar através desses exemplos, em filosofia o perigo está em falsear o caráter original dos problemas colocando-os em relação com uma meta-problemática que não lhes convém.

2. Essa observação permite compreender todo o peso da tese bem conhecida de Bergson: "Em filosofia, um problema bem formulado é um problema resolvido." ${ }^{2}$. 
Enquanto que, em matemática, após ter formulado o problema, se investiga os dados adquiridos cuja combinação permitirá resolvê-lo, parece com efeito que, em filosofia, a própria posição do problema não é possível se não o considerarmos no interior do quadro da meta-problemática que lhe convém. Não se encontra em filosofia esta ordem linear e progressiva que encontramos ${ }^{13}$ em matemática. O pensamento filosófico é circular, os problemas que ele se coloca e os princípios pelos quais ele acredita poder resolvê-los são mutuamente dependentes, sem que haja por isso círculo vicioso. Que tenhamos em mente, por exemplo, os problemas da gênese da inteligência e da gênese da matéria na Evolução criadora [de Bergson]. Esses problemas nem seriam formulados se não tivéssemos a intuição de certa diminuição ou queda do elã vital, intuição que serve ao mesmo tempo para resolvê-los, mas que, por sua vez, é consolidada e reforçada por essa mesma solução. E, para considerar um exemplo extraído de uma filosofia de inspiração totalmente distinta, o problema da matéria, que é um velho problema, não seria resolvido como o é por Descartes, se esse último, no interior de sua meta-problemática, não formulasse a exigência de que a matéria fosse objeto de uma ideia clara e distinta. Mas o mecanismo universal, fundado sobre essa solução, consolida por sua vez esse princípio que não teria nenhum sentido se permanecesse sem aplicação.

3. O que acabamos de dizer nos dará condições de julgar uma tese curiosa do Sr. Gabriel Marcel sobre a "distinção entre o misterioso e o problemático. O problema é algo que se encontra, obstáculo no caminho. Ele está inteiramente diante de mim. Ao 
contrário, o mistério é algo em que me encontro engajado, que não está inteiramente diante de mim"14. "Filosofar, para Gabriel Marcel, diz o Sr. Thibon ao comentar essa passagem, consiste menos em elucidar um problema do que em participar de um mistério"15. De acordo com essa tese, o problema é público, ele se coloca de direito para todos e do mesmo modo para todos (Deus existe? O homem é livre?). Além disso, ele diz respeito à razão e à inteligência. $\mathrm{O}$ mistério é privado ou no máximo coletivo, existindo apenas para um grupo determinado de homens. Os iniciados que dele formam parte são modificados em seu ser mais do que o são no conhecimento. Porém, essa distinção só será admissível se o mistério se referir a uma religião revelada. Uma vez excluído esse traço, se pode afirmar que toda filosofia tende a uma sabedoria e a uma transformação íntima do homem. Ela também nos "engaja”, a posição de um problema é menos a de um "obstáculo no caminho" do que a expressão de uma intuição profunda que se revela a nós por intermédio desse mesmo problema.

Conclui-se, então, em geral, que os problemas filosóficos não existem em si mesmos, separadamente, de modo que pudéssemos redescobri-los idênticos, mas que eles são momentos em um pensamento filosófico de conjunto que contém sua formulação e sua solução. Seria preciso ainda verificar como essa concepção permitiria vislumbrar um progresso real na filosofia, com o qual, à primeira vista, ela parece pouco compatível. 


\section{NOTAS}

${ }^{1}$ In: Études de philosophie antique. Paris: P.U.F., 1955. P. 10-16.

${ }^{2}$ Professor adjunto na Universidade Federal de Goiás (UFG) - Regional Goiás. E-mail: pjonas@gmail.com. Para a tradução, utilizamos para fins de comparação a tradução para o espanhol de Gonzalo Montenegro, publicada na revista Fermentario, n 7, 2013.

${ }^{3}$ Ed. Friedlein, p.77, 7. [Cf. mais abaixo, p. 129.]

${ }^{4} 530$ B. ["É com problemas, portanto, que nos dedicaremos à astronomia, tal como à geometria; e dispensaremos o que há no céu, se quisermos realmente tratar de astronomia, tornando útil, de inútil que era, a parte naturalmente inteligente da alma”. (N.T.)].

${ }^{5}$ Proclus, 77, 20.

${ }^{6} \mathrm{I}, 4,101$ b 29.

7 De um modo bem artificial, Proclus parece fazer ingressar essa marca característica na definição do problema matemático, quando diz: "inscrever um ângulo reto em um semicírculo não cria um problema, pois o ângulo ali inscrito será sempre reto. Dividir uma reta em partes iguais cria um problema, porque também podemos dividi-la em partes desiguais". O caso é muito diferente, pois se trata de dois problemas distintos e não de uma alternativa na qual os termos se excluem reciprocamente.

${ }^{8}$ Em Études de philosophie moderne, p. 156-157, diz Émile Bréhier: “Todo problema, como tal, nasce quando o espírito está em uma situação intermediária entre a ignorância e o saber. Não há problema para o ignorante; não há mais problema para o sábio. A noção mesma de problema está ligada à noção de filosofia, ou seja, do desejo ou do amor pela sabedoria. (...) A elucidação de um problema é sempre penetração do real.". [N.T.].

${ }^{9} \mathrm{Na}$ Ética de Espinosa, que segue, todavia, o método euclidiano, não há sinal de problema.

${ }^{10}$ Conferir, a esse respeito, as excelentes observações de Heinrich Barth, Philosophie der praktischen Vernunft, 1927, p. 84, 19.

${ }^{11}$ De acordo com Gonzalo Montenegro, se trata de um "procedimiento dialéctico que consiste en que un cambio conduce a algo hasta su género opuesto. La frase se encuentra en Aristóteles en Analitica posteriora, 7, 75 a 38”. Cf. sua tradução em Fermentario, no 7, 2013, p. 6n. [N.T.]. 
${ }^{12}$ Cf. Bergson, Henri. O pensamento e o movente. São Paulo: Martins Fontes, 2006. Pode-se dizer que H. Bergson nos encaminha para uma pedagogia do problema, que considera muito mais importante a elaboração das questões do que a elaboração das respostas ou soluções. Vejamos mais alguns trechos a esse respeito: "Agora, o problema que esse homem se põe, acaso nós o resolveremos? Evidentemente não, mas nós não o pomos: aí reside nossa superioridade. (...) Tal é exatamente o efeito que produzem sobre nós certos 'grandes problemas', quando nos reinstalamos no sentido do pensamento gerador. Tendem para zero à medida que dele nos aproximamos, não sendo mais que o afastamento entre ele e nós. Descobrimos então a ilusão daquele que crê fazer mais ao pôr esses problemas do que ao não os pôr". [P. 69-70]. "Estimo que os grandes problemas metafísicos são geralmente malpostos, que eles frequentemente se resolvem por si mesmos quando lhes retificamos o enunciado, ou ainda que são problemas formulados em termos de ilusão, que se desvanecem assim que olhamos de perto os termos da fórmula". [P. 109]. "Digo que há pseudoproblemas e que são os problemas angustiantes da metafísica”. [P. 110]. [N.T.].

${ }^{13} \mathrm{Ou}$ que imaginamos ver, se seguirmos as teses do Sr. Gonseth e de outros matemáticos que pensam que as matemáticas são obrigadas a retornar a seus princípios e, isto, em razão mesmo do progresso que elas realizam.

${ }^{14} \mathrm{Du}$ refus à l'invocation, p. 96.

${ }^{15}$ Revue de philosophie, 1946, p.149. 